\title{
MINAT KUNJUNGAN WISATAWAN MUSEUM GUNUNGAPI MERAPI
}

\section{Suharto}

Akademi Pariwisata Stipary Yogyakarta, Indonesia. Email: hartamas1970@ gmail.com

\begin{abstract}
Histori Artikel

Submitted:

23 April 2019

Reviewed:

27 April 2019

Accepted:

30 April 2019

Published:

15 Mei 2019

This paper is based on exploratory studies conducted at the Merapi Volcano Museum (MGM) with the aim of finding out the factors that influence interest in tourist visits. The methodology used in this study is based on field studies, through observation instruments, interviews, and questionnaires. The research respondents were domestic tourists who were taken randomly, the snippet technique as the primary data source was several museum employees and managers. The factors of tourist interest are identified through three things, namely the attraction of objects, accessibility and amenities.The results of the study found that the three main factors driving tourists' interest in visiting the Merapi Volcano museum were mainly due to the presence of amenities, especially in the provision of vast parking lots, the presence of new Merapi Park destinations, the presence of toilets and the existence of various tourist facilities typical of Kaliurang. The existence of the facilities provided by this management has been responded positively by the tourists as expected by management.
\end{abstract}

Keywords: Amenities, Merapi Volcano Museum, atraction.

\section{PENDAHULUAN}

Kabupaten Sleman adalah salah satu Kabupaten yang menjadi bagian dari Daerah Istimewa Yogyakarta. Kabupaten ini merupakan kabupaten terbesar di Daerah Istimewa Yogyakarta, dengan luas mencapai 574,82 $\mathrm{KM}^{2}$. Kabupaten Sleman memiliki berbagai daya tarik wisata yang beragam jenisnya mulai dari wisata budaya, wisata museum, wisata alam, wisata kuliner, dan berbagai jenis wisata lainnya.Salah satu daya tarik wisata di Kabupaten Sleman berada di kawasan Kaliurang, yang merupakan bagian dari lereng gunung Merapi. Berbagai objek terdapat di kawasan ini, seperti : Telaga Putri, Taman Rekreasi Kaliurang, beberapa gua peninggalan Jepang, Museum Ullen Sentalu, dan Museum Gunungapi Merapi, yang merupakan pokok bahasan dalam penelitian ini.
Museum Gunungapi Merapi merupakan sebuah museum yang berada di kawasan Kaliurang, tepatnya berada di Dusun Banteng, Desa Hargobinangun, Kecamatan Pakem, Kabupaten Sleman.Museum ini berisi berbagai koleksi yang berkaitan dengan kegunungapian di Indonesia maupun dunia, khususnya Gunung Merapi. Pembangunan Museum Gunungapi Merapi diprakarsai oleh Kementrian Energi dan Sumber Daya Mineral (ESDM), yang bekerjasama dengan Pemerintah Daerah Istimewa Yogyakarta (DIY), dan Pemerintah Daerah Kabupaten Sleman (Pemda 2 Kab. Sleman).

Museum Gunungapi Merapi karena selain dari jumlah koleksi yang beragam dan keunikan bangunannya, sampai saat ini masih banyak pengunjung dari luar maupun dari Yogyakarta yang mengunjungi museum tersebut. Wisatawan yang datang untuk 
berkunjung ke Museum Gunungapi Merapi tidak terlepas dari daya tarik wisata yang ditawarkan oleh pihak manajemen museum. Wisatawan akan melakukan kunjungan ke sebuah destinasi pariwasata karena adanya minat yang timbul dari dalam diri untuk melakukan kunjungan wisata. Minat itu sendiri merupakan kecenderungan dan kegairahan yang tinggi atau keinginan yang besar terhadap sesuatu (Kamus Besar Bahasa Indonesia ). Faktor - faktor yang diduga mempengaruhi minat kunjungan wisatawan ke Museum Gunungapi merapi adalah dari Atraksi, Aksesibiltas dan Amenitas.

Oleh karena itu tulisan hasil penelitian ini menyoroti tentang pengaruh daya tarik (atraksi, aksesiblitas, amenitas) yang ada di Museum Gunungapi Merapi sehingga dapat menarik minat kunjungan wisatawan.Berdasarkan latar belakang masalah yang telah dikemukakan, maka rumusan masalah yang akan dicari pemecahannya yaitu : Apakah minat kunjungan wisatawan di Museum Gunungapi Merapi dipengaruhioleh variabel komponen daya tarik wisata yaitu; atraksi, aksesibilitas, amenitas?

Dari masalah di atas maka luaran yang akan dicapai yaitu apakah terjadi korelasi antara minat kunjungan dengan komponen daya tarik yang mencakup atraksi, aksesibilitas dan amanitas. Dari berbagai komponen daya tarik komponen manakah yang palingdominanmempengaruhi

minatkunjungan wisatawan.

\section{LITERATURE REVIEW}

\section{Pariwisata dan Wisatawan}

Menurut Suwena (2010) mendeskripsikan pengertian pariwisata adalah gejala dari pergerakan manusia secara temporer dan spontan dalam rangka memenuhi kebutuhan dan keinginan tertentu. Selanjutnya dijelaskan bahwa pariwisata memiliki beberapa karakter yaitu :

1. Perjalanan itu dilakukan untuk sementara.
2. Perjalanan itu dilakukan dari suatu tempat ke tempat lainnya.

3. Perjalanan itu walaupun ada bentuknya harus dikaitakan denganpertamasyaan dan rekreasi.

4. Orang-orang yang melakukan perjalanan tersebut tidak untuk mencari nafkah ditempat yang dikunjungi olehnya dan semata-mata sebagai konsumen di tempat tersebut.

Sedangkan wisatawan menurut UndangUndang Kepariwisataan Nomor 10 Tahun 2009, wisatawan adalah orang yang melakukan wisata.Wisatawan yang berkunjung ke suatu daerah biasanya benarbenar ingin menghabiskan waktunya untuk bersantai, menyegarkan fikiran dan benarbenar ingin melepaskan diri dari rutinitas kehidupan sehari-hari. Jadi bisa juga dikatakan wisatawan adalah seseorang yang melakukan perjalanan dari suatu tempat lain yang yang jauh dari rumahnya bukan dengan alasan rumah atau kantor (Kusumaningrum, 2009).

Christopher dalam Pendit (2006), wisatawan adalah seseorang yang mengadakan perjalanan untuk melihat sesuatu yang lain dan kemudian mengeluh bila ia membayar sesuatu yang tidak sesuai.

\section{Minat Wisatawan}

Menurut kamus besar bahasa Indonesia minat adalah kecenderungan dan kegairahan yang tinggi atau keinginan yang besar terhadap sesuatu.Minat adalah rasa lebih suka dan rasa keterikatan pada suatu hal atau aktivitas (Djaali, 2011). Minat adalah sebagai suatu pemusatan perhatian yang tidak disengaja terlahir dengan penuh kemauannya dan tergantung dari bakat serta lingkungannya (Sujanto, 2004).

\section{Museum}

Museum berasal dari kata Yunani mouseion yang berarti kuil untuk Sembilan Dewi muze, anak Dewa Zeus yang dijadikan lambang berbagai bidang ilmu pengetahuan dan kesenian.Museum juga pernah diartikan sebagai tempat kumpulan pengetahuan dalam bentuk karya tulis, tempat koleksi realita bagi 
lembaga atau perkumpulan ilmiah, dan lainlain.Pengertian museum tersebut dari waktu ke waktu terus berubah sesuai dengan situasi dan kondisi saat ini.Akan tetapi, pada dasarnya pengertian museum tidak berubah karena landasan ilmiah dan kesenian tetap menjiwai arti museum sampai saat ini (Sutaarga, 1998).

Museum adalah lembaga, tempat penyimpanan, perawatan, pengamanan dan pemanfaatan benda-benda bukti materil hasil budaya manusia serta alam dan lingkungannya guna menunjang upaya perlindungan dan pelestarian budaya bangsa (Peraturan Pemerintah No.19 Tahun 1995 Pasal 1 ayat (1)).

\section{Daya Tarik Wisata}

Menurut Undang-Undang Republik Indonesia Nomor 10 Tahun 2009 tentang Kepariwisataan, Daya tarik wisata adalah segala sesuatu yang memiliki keunikan, keindahan, dan nilai yang berupa keanekaragaman kekayaan alam, budaya, dan hasil buatan manusia yang menjadi sasaran atau tujuan kunjungan wisatawan.

Sesuatu yang menarik dan menyebabkan wisatawan berkunjung kesuatu tempat/daerah/Negara itu disebut daya tarik atau atraksi wisata. Oleh sebab itu, daya tarik wisata ini dapat dikelompokkan ke dalam tiga jenis, yaitu objek wisata : alam, budaya, dan buatan (Sammeng, 2000)

Menurut Wardhani (2008), suatu daerah dikatakan memiliki daya tarik wisata bila memiliki sifat :

1. Keunikan, contoh : bakar batu di Papua, upacara memotong hewan dan lain-lain.

2. Keaslian, contoh : alam dan adat yang dilakukan dalam kehidupan sehari-hari.

3. Kelangkaan yang sulit ditemui di daerah/ negara lain.

4. Menumbuhkan semangat dan memberikan nilai bagi wisatawan.

Sebuah daerah yang mempunyai daya tarik wisata dapat dikatakan layak dikunjungi wisatawan bila ada tiga kegiatan yang dapat dilakukan di tempat tersebut,yaitu:
1. Something to see (sesuatu yang dapat dilihat), seperti keindahan/keunikan alam, bangunan sejarah, kesenian/budaya setempat.

2. Something to do (sesuatu yang dapat dilakukan), seperti naik sampan, mencoba makanan tradisional, menari dengan penari lokan dan lain-lain.

3. Something to buy (sesuatu yang dapat dibeli), untuk memenuhi kebutuhan wisatawan untuk berbelanja, seperti souvenir dan kerajinan rakyat yang dianggap para wisatawan sebagai barang yang menarik sebagai oleh-oleh untuk dibawa pulang ketempat asal masingmasing.

Selanjutnya dijelakan bahwa para wisatawan ketika akan berkunjung ke suatu destinasi disamping ingin melakukan berbagai kegiatan yang sudah diebutkan di atas akan mempertimbangkan berbagai hal yang dikenal dengan 5 A menurut wardhani (2008), yaitu (aksesibilitas, akomodasi, atraksi, aktivitas, amenitas). 5 A seringkali dijadikan pertimbangan dalam menentukan daya tarik wisata, berikut penjelasannya :

\section{Aksesibiltas}

Aksesiblitas yaitu kemudahan untuk dikunjungi dan memiliki jalan yang dapat dilalui oleh kendaraan.Lokasi wisata yang layak, aman, nyaman dan dapatdijangkau/ditempuh oleh wisatawan secara individu maupun rombongan dan adanya sarana penunjang transportasi, seperti kelayakan dan kenyamanan, serta keamanan jalan menuju lokasi.Kecuali bagi wisatawan adventure, yang mampu menelusuri lokasi wisata dengan berjalan kaki, namun pada jarak tertentu. Contoh: transportasi yang dapat menuju ke tempat lokasi wisata adalah pesawat udara, kapal laut, kereta api, bus, minibus, mobil, motor, sepeda, becak dan lain-lain.

\section{Akomodasi}

Akomodasi merupakan kemudahan mendapatkan/ada tempat penginapan yang layak bersih dan ramah/menyenangkan.Terdapat tempat untuk 
bermalam dan beristirahat yang layak, aman, dan memenuhi persyaratan kesehatan/sanitasi yang sehat. Di antaranya: hotel, hostel, losmen, guest house, caravan, sewa tenda, ataupun rumah penduduk yang memang disediakan bagi wisatawan.

\section{Atraksi}

Atraksi adalah dalam kemudahan dalam melihat atraksi yang khas di lokasi wisata. Adanya atraksi atau objek wisata yang dikelola oleh pemerintah/masyarakat setempat yang layak serta aman untuk dikunjungi wisatawan.Natural : pantai, laut, hutan, alam, telaga, gunung. Man made : museum, candi, taman, monument. Culture : seni, adat, tempat bersejarah, situs.

\section{Aktivitas}

Aktivitas adalah kemudahan dan adanya sarana fasilitas untuk melakukan kegiatan yang menyenangkan dan aman di daerah tersebut.Adanya aktivitas yang layak dilakukan wisatawan dengan aman, dapat dipantau keselamatannya.Diantaranya : mendaki gunung, menyelam, ski, berenang, berjalan santai, menonton pertunjukan, menikmati pemandangan dan lain-lain.

\section{Amenitas}

Amenitas merupakan fasilitas lain yang menunjang perjalanan wisata seperti telepon, penukaran uang, toko souvenir, dan lain-lain. Tersedianya fasilitas-fasilitas yang diperlukan oleh wisatawan seperti : bank, money changer, ATM, alrkunjungan yang tersistemdenganbaik, rumah makan, toilet yang memadai, kantor pos, toko cinderamata, pasar, jaringan internet, bangku taman dan lain-lain.

\section{METODE PENELITIAN}

Populasi dan sampel dari penelitian ini adalah wisatawan yang berkunjung ke Museum Gunungapi Merapi. Jumlah yang diharapkan adalah 100 wisatawan yang diambil melalui metode insidential sampling yaitu teknik penentuan sampel berdasarkan kebetulan, yaitu siapa saja yang secara kebetulan/insidential bertemu dengan peneliti yang dapat digunakan sebagai sampel, bila dipandang orang yang kebetulan ditemui itu cocok sebagai sumber data (Sugiyono, 2013). Dalam teknik sampling ini yang dijadikan anggota sampel adalah apa atau siapa saja yang kebetulan dijumpai di tempat-tempat tertentuPengumpulan data dilakukana melalui observasi dan penggunaan angket dengan skala likert untuk mengungkap pendapat para responden tentang atraksi , asesibilitas dan amenitaas Museum Gunungapi Merapi.

Variabel yang digunakan dalam penelitian ini terdiri dari variabel bebas (X) dan terikat (Y). Daya Tarik Wisata sebagai variabel bebas (X) terdiri dari $\mathrm{X}_{1}$ (variabel atraksi), $\mathrm{X}_{2}$ (aksesibilitas) dan $\mathrm{X}_{3}$ (amenitas). Indikator variabel atraksi sebagai $\mathrm{X}_{1}$ mencakup :Keunikan daya tarik wisata, Keanekaragaman daya tarik wisata dan Edukasi dalam daya tarik wisata. Indikator untuk $\mathrm{X}_{2}$ mencakup: Letak daya tarik wisata,Kondisi jalan menuju daya tarik wisata dan Arah penunjuk jalan menuju daya tarik wisata. Sedanagkan untuk indikator $\mathrm{X}_{3}$ mencakup : keberadaan Toilet, Toko cinderamata/pasar senidan Area parkir. Untuk Variabel terikat (Y) yaitu minat kunjungan yang ada pada diri wisatawan diukur melalaui respon yang diberikan oleh wisatawan pada masing-masing variable bebas dengan berpedoman pada skala Likert yang dimodifikasi melalui empat skor yaitu Sangat Setuju skor 4, Setuju skor 3, Tidak Setuju skor 2, dan Sangat Tidak Setuju skor 1 (Arikunto, 2010)

Teknik analisis yang digunakan untuk menguji pengaruh antara variabel bebas terhadap variabel terikat adalah regresi linier berganda tiga variabel.Analisis regresi linier berganda digunakan untuk melihat pengaruh dan memprediksi nilai suatu variabel independen terhadap variabel dependen (Santosa, 2016).Untuk mengetahui apakah variabel independen yang meliputi atraksi $\left(\mathrm{X}_{1}\right)$, aksesibilitas $\left(\mathrm{X}_{2}\right)$ dan amenitas $\left(\mathrm{X}_{3}\right)$ berpengaruh secara signifikan atau tidak 
terhadap variabel dependen yang meliputi minat kunjungan wisatawan (Y).

\section{HASIL DAN PEMBAHASAN}

Persamaan Garis Regresi dan Uji Parsial antara Variable Predictor terhadap Variable Kriterium
Hasil uji regresi linier ditunjukkan dalam persamaan regresi berdasarkan hasil olah data dari 100 wistawan yang dipilih sebagai responden penelitian. Hasil olah data melalui program SPSS tampak pada table berikut :

Tabel 1

Hasil Analisis Regresi Linier Berganda

Coefficients $^{\mathrm{a}}$

\begin{tabular}{|c|c|c|c|c|c|c|}
\hline \multirow[b]{2}{*}{ Model } & & \multicolumn{2}{|c|}{$\begin{array}{l}\text { Unstandardized } \\
\text { Coefficients }\end{array}$} & \multirow{2}{*}{$\begin{array}{c}\text { Standardized } \\
\text { Coefficients } \\
\text { Beta } \\
\end{array}$} & \multirow[b]{2}{*}{$\mathbf{t}$} & \multirow[b]{2}{*}{ Sig. } \\
\hline & & B & Std. Error & & & \\
\hline \multirow[t]{4}{*}{1} & (Constant) & 2.795 & .997 & & 2.803 & .006 \\
\hline & $\mathrm{x} 1$ & .269 & .099 & .259 & 2.701 & .008 \\
\hline & $\mathrm{x} 2$ & .216 & .093 & .234 & 2.324 & .022 \\
\hline & $\mathrm{x} 3$ & .289 & .094 & .287 & 3.073 & .003 \\
\hline
\end{tabular}

Dependent Variable : y

Sumber: Data Primer, 2019

Persamaan garis regresi berdasarkan hasil olah data seperti pada tabel di atas merupakan bentuk persamaan prediksi yang bersifat positip, yaitu $Y=2.795+\mathbf{0 . 2 6 9 X _ { 1 }}$ $+\mathbf{0 . 2 1 6}_{2}+\mathbf{0 . 2 8 9}_{\mathbf{3}}$. Dari persamaan ini dapat dijelaskan bahwa ketiga faktor yaitu atraksi, aksesibilitas dan amenitas merupakan sebuah predictor terhadap keputusan wisatawan dalam bekunjung ke Museum Gunungapi Merapi, artinya bahwa ketiga faktor di atas dapat dipakai sebagai salah satu dimenasi untuk memprediksi seberapa besar tingkat kunjungan wisatawan.

Pengujian secara parsial dapat dilihat melalui besaran nilai koefisien masing-masing variabel. Ketentuan yang dipergunakan dalam menilai besaran kontribusi variable bebas terhadap variable terikat (predictor terhadap kriterium) yaitu nilai kritis (alpha $5 \%$ atau 0.05 ) jika nilainya lebih kecil dari 0.05 maka kontribusi dinyatakan signifikan.
Jika dilihat dari besaran yang ada maka variabel $\mathrm{X}_{3}$ (amenitas) merupakan variabel yang paling berkontribusi dalam menyumbang kehadiran wisatawan di Museum Gunungapi Merapi.

Bangunan museum ialah bangunan yang dapat berfungsi untuk menyimpan, merawat, mengamankan, dan memanfaatkan koleksi.Bangunan pokok meliputi beberapa ruang sebagai berikut: (1)Ruang pameran tetap, (2)Ruang pameran temporer, (3)Ruang auditorium, (4)Ruang kantor/administrasi, (5)Ruang perpustakaan, (6)Ruang laboratorium, (7)Runag penyimpanan koleksi (storage), (8)Ruang edukasi, (9)Ruang transit koleksi, (10)Bengkel kerja preparasi.

Konstanta sebesar 2.795 diartikan bahwa varibel dalam penelitian ini ditiadakan, maka besran wistawan yang berkunjung ke Museum sebesar 2.795 satuan, tentunya faktor ini diakibatkan oleh faktor yang 
berada di luar variabel yang sedang diteliti misalnya saja faktor harga, faktor loyalitas wisatawan, ataupun faktor kebutuhan untuk edukasi, untuk melakukan sesuatu sebgai suatu kebutuhan wisatawan. 
Pengujian Simultan Variable Predictor Pengujian simultan (Uji F) terlihat dalam terhadap Variable Kriterium analysis covarince (ANOVA) seperti pada tabel berikut :

Tabel 2

Hasil Uji F

\begin{tabular}{|c|c|c|c|c|c|c|}
\hline \multicolumn{7}{|c|}{ Anova $^{b}$} \\
\hline Model & & Sum of Squares & Df & Mean Square & $\mathbf{F}$ & Sig. \\
\hline \multirow[t]{3}{*}{1} & Regression & 58.902 & 3 & 19.634 & 21.205 & $.000^{\mathrm{a}}$ \\
\hline & Residual & 88.888 & 96 & .926 & & \\
\hline & Total & 147.790 & 99 & & & \\
\hline
\end{tabular}

Sumber: Data Primer, 2019

Uji $F$ digunakan untuk pengujian hipotesis atau mengetahui pengaruh variabel bebas yang meliputi atraksi, aksesiblitas dan amenitas secara simultan (bersama-sama) terhadap variabel terikat berupa minat kunjungan wisatawan di Museum Gunungapi Merapi. Pada pengujian ini untuk memutuskan menerima atau menolak hipotesis menggunakan dasar nilai probabilitas dibandingkan dengan tingkat kepercayaan (level of significance $95 \%$ atau alpha sebesar 5\%. Berdasarkan ketentuan penerimaan atau penolakan jika nilai probabilitas $<0.05$, maka hipotesis nihil akan ditolak.

Hasil analisis menunjukkan bahwa besarnya nilai probabilitas adalah 0.000 maka hipotesis nihil ditolak sehingga dapat diputuskan bahwa ketiga variable bebas (atraksi, aksesibilitas dan amenitas) secara simultan memberikan pengaruh yang signifikan terhadap tingkat kunjungan wisatawan di Museum Gunungapi Merapi. Atau dapat dijelaskan bahwa banyak sedikitnya jumlah wisatawan yang datang ke museum dapat dipredksikan melalaui besarnya variable atraksi, aksesibilitas dan amenitas. Artinya, semakin baik daya tarik yang ada, semakin mudah diakses oleh wisatawan dan semakin besar amenitas untuk kepentingan wisatawan yang disediakan oleh manajemen maka akan semakin besar tingkat kungjungan wistawan ke museum tersebut.

Besarnya nilai $F$ adalah 21.205 ditentukan besarnya nilai rata-rata kuadrat dari nilai regresi dan nilairesidu (mean square regression and residual) semakin besar nilai kuadrat regresi dan semakin kecil nilai kuadrat residu maka akan semakin besar nilai F yang berarti semakin berpengaruh variable predictor terhadap variable kriterium. Besarnya nilai rata-rata kuadrat tidak lain adalah kekuatan hubungan (nilai korelasi) antara variable daya tarik, aksesibilitas maupun amenitas yang tersedia dari museum dengan variable minat kunjungan wisatawan.

\section{Uji Determinasi Uji R Square}

Uji ini ditujukan untuk mengetahui seberapa besar kontribusi variabel predictor menentukan besarnya variable kriterium. Table berikut hasil anaalisis data yang mengilustrasikan besaran nilai r square $\left(r^{2}\right)$. 
Tabel 3

\begin{tabular}{ccccc}
\hline Model & $\mathbf{R}$ & R Square & $\begin{array}{c}\text { Model Summary } \\
\text { Adjusted R Square }\end{array}$ & Std. Error of the Estimate \\
\hline 1 & $.631^{\mathrm{a}}$ & .399 & .380 & .962 \\
\hline
\end{tabular}

Sumber: Data Primer, 2019

Dengan ketentuan penggunaan nilai $\mathrm{r} 2$ adalah nilai penyesuaian (adjusted) besarnya yaitu 0.38 atau sebesar $38 \%$. Artinya variable bebas dapat dipakai untuk memeprediksi besarnya minat wisatawan adalah sebesar 38 $\%$ saja sedangkan sisanya sebesar $62 \%$ diprediksikan dari variable lain yang tidak dimasukan dalam penelitian ini.

\section{KESIMPULAN}

Berdasarkan hasil pembahasan dapat disimpulkan bahwa ketiga dimensi sebagai predictor dalam persamaan regresi memberikan kontribusi yang signifikan terhadap keputusan wisatawan untuk berkunjung di Museum Gunungapi Merapi. Secara kuanitatif besarnya kontribusi adalah $38 \%$

Dimenasi amenitas merupakan demiensi paling dominan, hal ini ditunjukkan melalui berbagai fasilitas yang disediakan untuk kepentingan tamu seperti keberadaan arena parkir, ruang edukasi, ruang perpustakaan, ruang laboratorium, ruang penyimpanan koleksi (storage), ruang transit koleksi.

Untuk meningkatkan jumlah kunjungan wisatawan kedestinasi museum di Yogyakarta direkomendasikan kepada pengelola museum untuk melakukan pembaharuan dengan memperkaya koleksi, melakukan berbagai terobosan dalam pemasaran dengan mengandalakan pada media sosial (medsos) yang ada era teknologi ini sudah dikuasai oleh masyarakat sehingga dengan mudah diakses.

Dari hasil penelitian masihada $62 \%$ peluang yang bias dihipotesiskan untuk dikembangkan di luar faktor penelitian. Hipotesis yang direkomendasikan adalah kampanye kunjungan museum yang terintegrasi dengan destinasi yang ada disekitarnya seperti volcano tour, sport tourism downhill, taman wisata Kaliurang dan berbagai spot foto yang ada di Kaliurang Park.

\section{REFERENSI}

Arikunto, Suharsimi. 2010. Prosedur Penelitian. Jakarta: Rineka Cipta.

Djaali, H. 2011. Psikologi Pendidikan. Jakarta: Bumi aksara

Kusumaningrum, Dian. 2009. Persepsi Wisatawan Nusantara Terhadap Daya tarik Wisata Di Kota Palembang. Tesis PS Magister Kajian Pariwisata: Universitas Gadjah Mada.

Pendit, S Nyoman. 2006. Ilmu Pariwisata Sebuah Pengantar Perdana. Jakarta: Pradnya Pramita.

Peraturan Pemerintah No.19 Tahun 1995 Pasal 1 ayat (1)

Sammeng, Andi Mappi. 2000. Cakrawala Wisata. Jakarta: Gramedia

Santosa. 2016. Statistik Hospitalitas. Yogyakarta: Deepublish

Sugiyono. 2013. Metopen Kuantitatif Kualitatif dan R\&D. Alfabeta: Bandung.

2014. Statistika untuk Penelitian. Alfabeta: Bandung.

Sujanto, Agus. 2004. Psikologi Umum. Jakarta: Rineka Cipta

Sutaarga, M. Amir. 1998. Pedoman penyelaenggaran dan Pengelolaan Museum. Jakarta: Proyek pembinaan 
permuseuman Jakarta, Direktorat

Jendral Kebudayaan, Depdikbud

Suwena,I Ketut dan Widyatmaja. 2010.

Pengetahuan Dasar Ilmu Pariwisata.

Udayana University Pers : Bali.

Undang-Undang RI No 10 Tahun 2009

tentang Kepariwisataan Republik Indonesia.

Wardhani, U, E, dkk. 2008. Usaha Perjalan

Wisata Jilid 1. Jakarta : Direktorat

Pembinaan Sekolah Menengah

Kejuruan, Direktorat Jenderal

Manajemen Pendidikan Dasar dan

Menengah, Departemen Pendidikan

Nasional.

.2008. Usaha Perjalan Wisata Jilid 2.

Jakarta : Direktorat Pembinaan

Sekolah Menengah Kejuruan,

Direktorat Jenderal Manajemen

Pendidikan Dasar dan Menengah,

Departemen Pendidikan Nasional.

Yoeti, Oka A. 2001. Ekowisata Pariwisata

Berwawasan Lingkungan Hidup.

Jakarta: Partja. 